\title{
Performance Evaluation of Cloud Database Security Algorithms
}

\author{
*Mr.Srinu Banothu ${ }^{1}$, Govardhan $\mathrm{A}^{2}$, and Karnam Madhavi ${ }^{3}$ \\ ${ }^{1}$ Research Scholar, JNTUH, and Assistant Professor, Dept of CSE, Vignan Institute of Technology and Science \\ Hyderabad, India \\ ${ }^{2}$ Professor, Dept. of CSE, \& Rector JNTUH, Hyderabad, India, \\ ${ }^{3}$ Professor \& HOD, Dept of CSE, GRIET, Hyderabad, India
}

\begin{abstract}
Cloud computing is a group of servers providing the on demand computing services to the users on rental basis. One of the services providing by the cloud is Data Storage as a Service. In Data Storage as a Service user will outsource their sensitive data to cloud storage environment, where the users data will be stored and whenever user needs data, they will access from the cloud storage from anywhere and anytime using any device connected to the internet. One of the critical issues in this is data security. When user outsources their sensitive data to cloud vendor, the cloud vendor may leak the user's sensitive data to third persons because vendor is not a trusted party. To overcome these problems there are many authors suggested different security algorithms. In this research we studied and evaluating the performances of those security algorithms and proposing a better solution, which provides best security to data stored in cloud databases.
\end{abstract}

\section{Introduction}

Cloud computing is a technology providing online services to the users on rental basis, in order to reduce the cost and maintenance burden of a user or an enterprise. Cloud computing providing the various types of services like as Software-as-aService(SaaS),Platform-as-a-Service(PaaS),

Infrastructure-as-a-Service (IaaS) and Database-as-aService(DaaS). The SaaS, in which the service providers hosts applications for customers and make them available to access via internet. It is a software distribution model. In IaaS, the cloud service providers keep the IT related Infrastructures such as operating systems, hardware equipments, storage systems, server and other software for customers, and make them available to access online on rental basis. PaaS allows the customer to access the cloud platform(i.e. Operating system and related hardware) online to create and deploy any software applications using programming languages. DaaS, provides online data storage services, so that the customer can store their enterprise data into cloud databases on rental basis and access database from anywhere anytime by any device connected to internet. With this facility the data owner can outsource their huge amount of enterprise data to the cloud storage environment.

In this paper we consider the problem of data security in cloud storage, in which one party (User) owns a database and wants to outsource it to a second party (Service Provider), even though the trust of user in service provider is limited. User wants to be guarantee that the data they outsource is fully secured. Legal options, such as contracts, are available, but their effectiveness is often limited. For example, if the database is acquired by other company, it may be unclear whether the new owner is bound by the contract. As per Amazon opinion:"In the unlikely event that Amazon.com Inc., or substantially all of its assets are acquired, customer information will of course be one of the transferred assets“. If the data were encrypted, this problem will not arise. Ideally, the user would like to have the data encrypted and only give the cipher text to database service provider. But if database service provider is not trusted, he cannot participate in the encryption/decryption process. Usually database service provider does not only stores the data, but also processes non-trivial queries sent by user and therefore should be able to process these queries without decrypting the stored data.For protecting the sensitive data of users stored in cloud database, we need high standard database security algorithms. This paper is presenting the survey onexisting database security algorithms and discussing about merits and demerits of those algorithms. Also presenting about future research.

* Email: srinub1307@gmail.com 
The structure of this paper is as follows. Section 2 gives background study about Database Security and Section 3 gives brief about security algorithms. Section 4 gives the performance analysis of the various Security Algorithms and Section 5 presents our conclusions and ideas for future work.

\section{Background Study about Database Security}

In the wake of having seen the most cloud data security issues, at present the attention is on the wellbeing properties gave by the present databases and in a nutshell displaying the aftereffects of the investigation on these databases thinking about the input of extreme clients, individual tests and databases documentation. The chief boundless bundle and exclusive old databases, (for example, SQL Microsoft, Oracle, DB2, MySQL, PostgreSQL) still as cloud databases, (for example, Amazon SimpleDB, Google DataStore and Azure SQL) are picked for this investigation. to check the present databases, from a security motivation behind read, we have delineated 10 security criteria (see table 1): 1) Users recognizable proof and confirmation: recognizing the data clients in an exceptionally sheltered and unambiguous way to utilize the entrance controls in step with the privileges of each client. 2) Identification of strength: ensure that it's hard to seize ANd hold a personality while not right (for example parole power). 3) Rights partition: recognize different sorts of clients with predefined activities to isolate. 4) Information Access control: grant access to the hang on data exclusively to endorsed people. This entrance the board should allow shifted get to modes (perusing or potentially composing) and a variable unpleasantness (all informations or one or numerous database tables). 5) Integrity and classification of the hang on data: ensure that exclusively endorsed clients will alter the hang on data inside the server facilitating the database the executives framework and peruse imperative information. 6) Communications figuring: ensure the uprightness also, whenever required the secrecy of the solicitations and data changed between the varying types of gear actualizing or abuse the data administration for example trades between customers has (end-clients or heads) and furthermore the server facilitating the database the board framework or between servers just if there should arise an occurrence of an appropriated database the board framework (information replication). 7) Information covering: hide genuine data in counterfeit one to adulterate the measure of genuine data, explicitly once data ar underway, while allowing to look out just the $\$ 64000$ data. 8) Information concealing: utilize A procedure to trade touchy data and ensure that unique data can not be found or redesigned. This property is fantastically fundamental quite once data ar used with regards to application advancements and tests. 9) Audit administrations: $\log$ the occasions with respect to the gets to the database the board framework and ensure the honesty of the logs. this sort of administration is basic to direct a posteriori the gets to and identifies the clients United Nations organization surpass their privileges. 10)Certification: This last model issues the EAL (Evaluation Assurance Level) affirmation plot in seven levels that licenses examination of IT applications. For common applications, the EAL is for the most part somewhere in the range of one and $4+$ and for military applications somewhere in the range of five and seven.

Table 1: Comparative statement of traditional and cloud databases with several security criteria

\begin{tabular}{|c|c|c|c|c|c|c|c|c|}
\hline \multirow{3}{*}{$\begin{array}{l}\text { Datab } \\
\text { ase } \\
\text { Types } \\
\text { Prope } \\
\text { rties }\end{array}$} & \multicolumn{5}{|c|}{ Traditional Databases } & \multirow{2}{*}{\multicolumn{3}{|c|}{$\begin{array}{c}\begin{array}{c}\text { Cloud } \\
\text { Databases }\end{array} \\
\text { Owner } \\
\end{array}$}} \\
\hline & \multicolumn{3}{|c|}{ Owner } & \multicolumn{2}{|c|}{ Free } & & & \\
\hline & $\begin{array}{l}\text { Mic } \\
\text { ros } \\
\text { oft } \\
\text { SQ } \\
\text { L }\end{array}$ & $\begin{array}{l}\text { Or } \\
\text { acl } \\
\text { e }\end{array}$ & $\begin{array}{l}\text { IB } \\
\text { M } \\
\text { D } \\
\text { B2 }\end{array}$ & $\begin{array}{l}\text { My } \\
\text { SQ } \\
\text { L }\end{array}$ & $\begin{array}{l}\text { Pos } \\
\text { tgr } \\
\text { ey } \\
\text { SQ } \\
\text { L }\end{array}$ & $\begin{array}{l}\text { Am } \\
\text { azo } \\
\text { n } \\
\text { Sim } \\
\text { ple } \\
\text { DB } \\
\end{array}$ & $\begin{array}{l}\text { Goo } \\
\text { gle } \\
\text { Dat } \\
\text { aSt } \\
\text { ore }\end{array}$ & $\begin{array}{l}\text { A } \\
\mathrm{zu} \\
\text { re } \\
\mathrm{S} \\
\mathrm{Q} \\
\mathrm{L}\end{array}$ \\
\hline $\begin{array}{c}\text { Users } \\
\text { identifi } \\
\text { cation } \\
\text { and } \\
\text { authen } \\
\text { ticatio } \\
\text { n }\end{array}$ & $\sqrt{ }$ & $\sqrt{ }$ & $\sqrt{ }$ & $\sqrt{ }$ & $\sqrt{ }$ & $\sqrt{ }$ & $\sqrt{ }$ & $\sqrt{ }$ \\
\hline $\begin{array}{l}\text { Identif } \\
\text { ication } \\
\text { of } \\
\text { robust } \\
\text { ness } \\
\text { and } \\
\text { authen } \\
\text { ticatio } \\
n\end{array}$ & $\sqrt{ }$ & $\sqrt{ }$ & $\sqrt{ }$ & $x$ & $\sqrt{ }$ & $\sqrt{ }$ & $\sqrt{ }$ & $\sqrt{ }$ \\
\hline $\begin{array}{l}\text { Rights } \\
\text { separat } \\
\text { ion }\end{array}$ & $\sqrt{ }$ & $\sqrt{ }$ & $\sqrt{ }$ & $!$ & $x$ & $!$ & $!$ & $!$ \\
\hline $\begin{array}{c}\text { Data } \\
\text { Access } \\
\text { control }\end{array}$ & $\sqrt{ }$ & $\sqrt{ }$ & $\sqrt{ }$ & $\sqrt{ }$ & $\sqrt{ }$ & $!$ & $!$ & $\sqrt{ }$ \\
\hline $\begin{array}{l}\text { Integri } \\
\text { ty and } \\
\text { confid } \\
\text { entialit } \\
\text { y of } \\
\text { the } \\
\text { stored } \\
\text { data }\end{array}$ & $\sqrt{ }$ & $\sqrt{ }$ & $\sqrt{ }$ & $!$ & $\sqrt{ }$ & $x$ & $x$ & $x$ \\
\hline $\begin{array}{l}\text { Comm } \\
\text { unicati } \\
\text { ons } \\
\text { cipheri } \\
\text { ng }\end{array}$ & $\sqrt{ }$ & $\sqrt{ }$ & $\sqrt{ }$ & $\sqrt{ }$ & $\sqrt{ }$ & $\sqrt{ }$ & $\sqrt{ }$ & $\sqrt{ }$ \\
\hline Data & $x$ & $x$ & $x$ & $\times$ & $\times$ & $\times$ & $\times$ & $x$ \\
\hline
\end{tabular}




\begin{tabular}{|c|c|c|c|c|c|c|c|c|}
\hline $\begin{array}{c}\text { concea } \\
\text { lment }\end{array}$ & & & & & & & & \\
\hline $\begin{array}{c}\text { Data } \\
\text { Maski } \\
\text { ng }\end{array}$ & $\times$ & $\sqrt{ }$ & $\times$ & $\times$ & $\times$ & $\times$ & $\times$ & $\times$ \\
\hline $\begin{array}{c}\text { Audit } \\
\text { service } \\
\text { s }\end{array}$ & $\sqrt{ }$ & $\sqrt{ }$ & $\sqrt{ }$ & $\times$ & $\times$ & $\sqrt{ }$ & - & $\sqrt{ }$ \\
\hline $\begin{array}{c}\text { Certifi } \\
\text { cation }\end{array}$ & $\begin{array}{c}\text { EA } \\
\text { L1+ }\end{array}$ & $\begin{array}{c}\text { E } \\
\text { A } \\
\text { L4 } \\
+\end{array}$ & $\begin{array}{c}\text { E } \\
\text { A } \\
+\end{array}$ & $\times$ & $\begin{array}{c}\text { EA } \\
\text { L1 }\end{array}$ & $\times$ & $\times$ & $\times$ \\
\hline
\end{tabular}

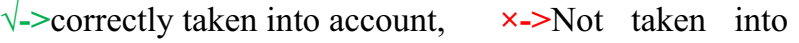
account, !->not correctly taken into account, - Not found relevant information

By these 10 criteria's, we can see inside the table that antiquated databases are amazingly verified. This can be strikingly valid for exclusive databases like Microsoft SQL and Oracle that zone unit extra develop than those utilized in mists that zone unit similarly new. The cloud data doesn't ensure data secrecy and a large portion of the cloud administration providers leave to the clients/customers to deal with the privacy of their data. In addition, in cloud databases like Amazon SimpleDB, data get to the board is given anyway not at a fine coarseness level. Truth be told, the entrance to a data is related to a client record or client job that has every one of the rights subsequently and it's unsuitable to restrain the entrance rights.

\section{Overview of Cloud Database Security Algorithms}

This research evaluates performances of the following algorithms

- Data concealment in a cloud database

- Multi-clouds database model

- The hoeppner security algorithm

\subsection{Data Concealment in A Cloud Database.}

Delettre [1] projected an information Concealment answer to produce the safety for the user's sensitive data within the cloud databases. In this technique some artificial information has been more in conjunction with the important information of the user, in order that it creates ambiguity to the unauthorized users, it cannot be simply known by the unauthorized users. During this technique we have an information concealment security element, it achieves the information security in cloud information. Data concealment security element consists of 3 sub-components:

$$
\begin{aligned}
& \text { - The prediction element, } \\
& \text { - } \quad \text { Data generator and }
\end{aligned}
$$

\begin{abstract}
Data marking.
The prediction element uses a basic however quick and economical prophetic model to outline the amount of artificial data vectors to insert, in addition to the vector marked to conceal real data.
\end{abstract}

The sub-part data generator gives the measure of counterfeit information vectors given by the prognosticative model. This data age must be done with regards to the language of the significant data noted 1 , all together that the stunning data can look as genuine data. The objective of the third sub-segment is to check the data vector to embed. This vector is plot as follows: $\mathrm{V}=(\mathrm{d} 1, \mathrm{t} 1, \mathrm{~m} 1),(\mathrm{d} 2, \mathrm{t} 2, \mathrm{~m} 2) \ldots . .(\mathrm{dk}, \mathrm{tk}, \mathrm{mk})$ any place $\mathrm{di}$ is that the ith data of the vector, ti the sort of this data, mi shows if this data ought to be stamped $(\mathrm{mi}=1)$ or not $(\mathrm{mi}=0)$ and $\mathrm{k}$ speaks to the measure of fields inside the data vector.

Conventional watermarking ways mark the data with regards to the data themselves and a mystery part noted exclusively by the genuine proprietor of the data. Therefore, when verificatory the stamping, if the measure of information| blessing isn't sufficient it is tough to confirm with cocksureness that the data have a place with the authentic information proprietor. Notwithstanding, inside the setting of this work, we might want to be in a situation from one data vector to comprehend with sureness that this vector might be a vector of genuine data or fake data while not knowing the contrary data vectors. Besides, generally watermarking ways corrupts incompletely the data in a very non-reversible way that isn't adequate for a couple very data seeing for instance a customer any place the name, address, and so on square measure vital to recognize her/him in an exceptionally unmistakable technique. Along these lines, we wolud like a checking system that imprints data continuously while not debasing them in a very non-reversible strategy.

To check genuine information vectors we utilize a similar standard as the watermarking techniques for example we utilize a private key known uniquely by the authentic proprietor of information to hash this private key connected with the information that must be stamped. At that point, from this hash are separated the $\mathrm{m}$ first bits to be connected with the information itself (for example the information that must be checked). A similar guideline is applied on fake information with the exception of that we change the $\mathrm{m}$ bits to have the option to separate fake information vectors from the genuine ones.

\subsection{Multi-Clouds Database Model}

In this segment, Mohammed A. Alzain [2] proposed another model called Multi-Clouds Database (MCDB). MCDB guarantees protection and security in cloud 
information storage area and it depends on multi-clouds service vendors and the confidential sharing algorithm. MCDB gives "cloud database" which allow clients with various kinds of database inquiries, for example, total and correct match and range question with the capacity to store any unique sorts of information, for example, video, pictures or records. The reason for the Alzain[2] display is to keep away from the danger of malignant insider in the cloud and to stay away from the coming up short of cloud administrations. The security dangers, for example, information interruption, information honesty and administration accessibility will be analyzed in the model.

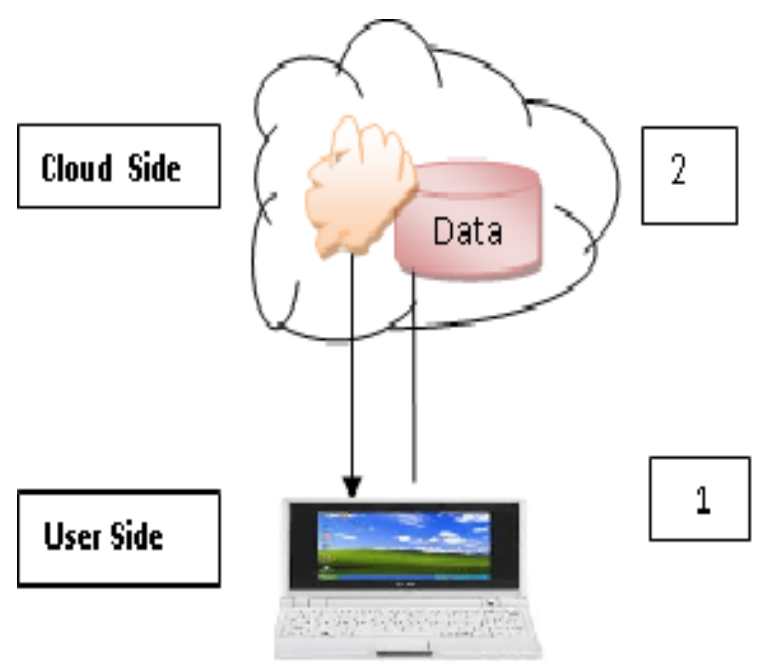

Figure 1. Overview of Cloud Environment

Figure 1 illustrates the general overview of cloud computing environment. Part 1 represents the client side, which sends data inquiries to server or instance such as in Amazon in cloud service provider (CSP) in part 2. The data source in part 2 stores the data in the cloud, which is required to be a trusted cloud, in addition to ensuring the privacy of any query that the client has made and for the security of the client stored data. A problem arises when we are not sure that cloud is a trusted service. Here is the Multi-Clouds Database Model architecture

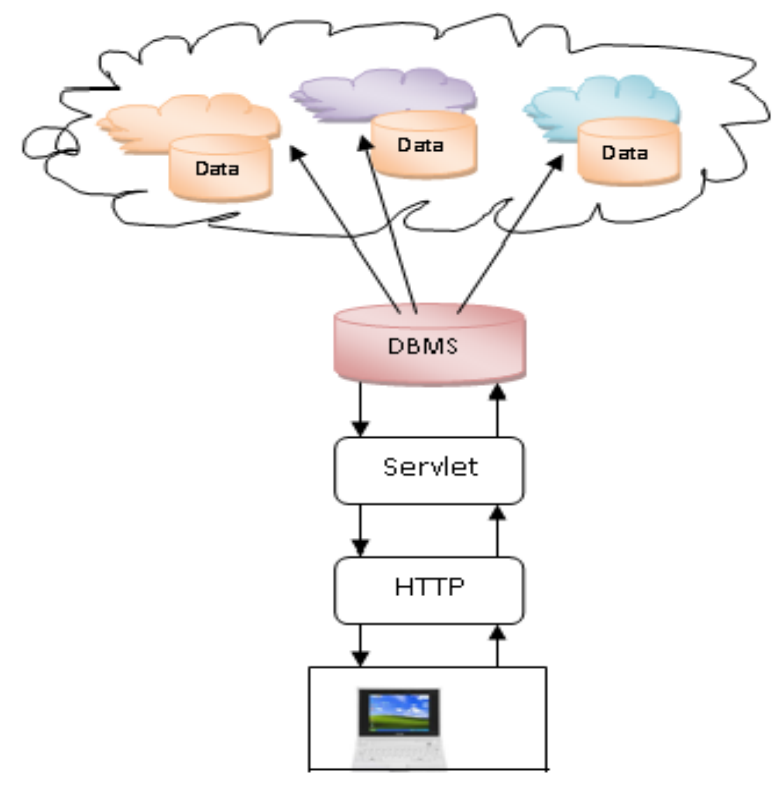

Figure 2. Multi Cloud computing model

MCDB provides cloud with database storage, in multiclouds service provider which is different from Amazon cloud service. MCDB model (see Figure 2) does not provide security by single cloud; rather security and privacy of data will be provided by applying multi shares technique [4] on multi-cloud providers. By doing so, it avoids the negative effects of single cloud, decreases the security risks from malicious insider in cloud computing environment, and decreases the negative impact of encryption techniques. MCDB retains security and privacy of user's data by replicating data among several clouds and by using the secret sharing approach. It deals with the database management system (data source) to manage and control the operations between the clients and the cloud service providers (CSP).

There are three MCDB layers (Table 2): the presentation layer, the application layer, and the data management layer. The presentation layer is having the end user's browser and HTTP server. The management layer is having the Database Management System (DBMS) and the database service provider. Database Management system communicates with the Servlet Engine through the JDBC protocol. Communication between components is with help of a secured private high speed network that uses secure protocols. 
Table 2: MCDB Layers

\begin{tabular}{|l|l|}
\hline Layer Name & Component \\
\hline Presentation layer & \\
\hline Application Layer & $\begin{array}{l}\text { Servlet } \\
\text { Engine }\end{array}$ \\
\hline $\begin{array}{l}\text { Data Management } \\
\text { Layer }\end{array}$ \\
\hline
\end{tabular}

\subsection{The Hoeppner Security algorithm}

The Hoeppner Security Algorithm [3] segments a table's information into a few little tables and stores in different clouds, probably facilitated by various Cloud Service merchants. Scattering the information will expand information accessibility (the clouds will normally duplicate a client's information over numerous host machines for simple access), however keep up information lack of definition. Information ought to be parceled so that no gathering of fields that would demonstrate implicating together is put away in a similar cloud to accomplish most noteworthy security. For instance, Social Security Numbers (SSNs) ought to be taken care of in a totally secluded cloud from any information that would append the SSN to its owner's character. After they are partitioned, for each record (checking the fake records) special identifier is given. The identifier is taken care of with all of the record's parts in the various mists, empowering the records to be combined later. This methodology is appeared in Figures 3 and 4 . The essential figure is a database table having genuine records (splendid green) and phony records (red).For each record in the table is given a one of a kind key worth, and afterward the records are isolated to make the tables in the second figure. The HSA separates the table dependent on the client's inclination. It very well may be separated into any number of tables, every one of which can be put away in a cloud of their decision. In Figure 3.3.2, the table is partitioned into four sections, one for each property, and each is put away in a different cloud. Each quality section parceled from a similar unique record has a similar key worth. That is the reason "S2", "Venkat", "20000", and "Bengulure" all have a key estimation of 1. They are for the most part sections of a similar record. These key qualities enable the table's parts to be effectively consolidated through a JOIN inquiry to build the first table in Figure 3. Information Fragmentation will be examined further [3]

\begin{tabular}{|l|l|l|l|}
\hline $\begin{array}{l}\text { S.N } \\
\text { O }\end{array}$ & SNAME & QUOTA & CITY \\
\hline S1 & $\begin{array}{l}\text { SUBRMANY } \\
\text { AM }\end{array}$ & 4000 & HYDERABAD \\
\hline S2 & VENKAT & 20000 & BENGULURE \\
\hline S3 & PRAVEEN & 10000 & $\begin{array}{l}\text { PEERJADIGU } \\
\text { DA }\end{array}$ \\
\hline S4 & RAJARAM & 10000 & UPPAL \\
\hline S5 & YADAIAH & 5000 & $\begin{array}{l}\text { SECUNDRAB } \\
\text { AD }\end{array}$ \\
\hline S6 & RAMESH & 2000 & $\begin{array}{l}\text { VIJAYAWAD } \\
\text { AJAMA }\end{array}$ \\
\hline S1 & NARESH & 7000 & BETHAHOLE \\
\hline S8 & MANO. & $\mathbf{9 0 0 0}$ & SURYAPET \\
\hline
\end{tabular}

Figure 3. Database Table

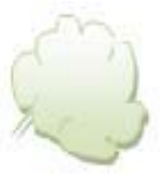

CLOUD1

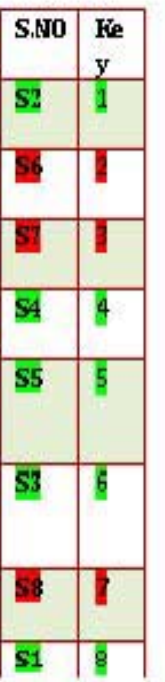

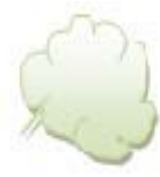

CLOUD2

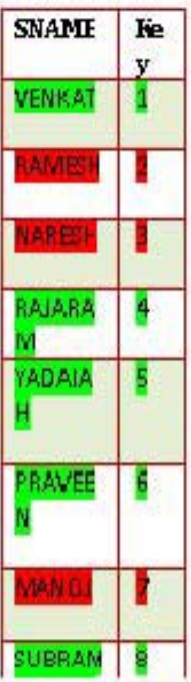

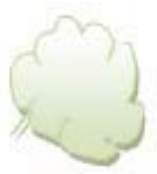

C.OUL 3

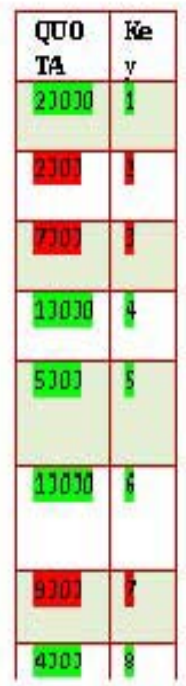

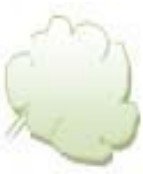

CLOUDL

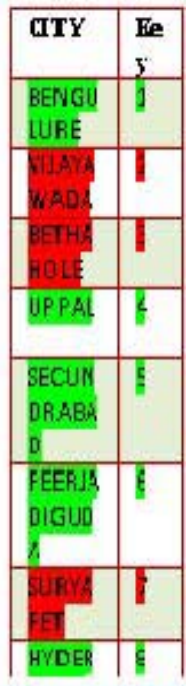

Figure 4. Records after fragmentation in Different Clouds

Hoeppner Security recipe utilizes fracture method to store and recover data. To shape the client's aptitude as consistent as possible, the essential move made once the client associates with their cloud group is to assemble exclusively the significant records and union them into one data read for comfort. So with respect to the combination to occur, a few information ought to be hang on in each cloud forming what records are 
genuine and which of them are bogus information. The personalities of the genuine records can't be hang on explicitly, however, since that may undermine the entirety of the wellbeing estimates that the Hoeppner Security recipe brings. Rather, the SSA is utilized to figure this information. Though the Hoeppner Security recipe is running, a stock of genuine records is kept up.

At whatever point the database is submitted, first the rundown is encoded into a number qualities called the "Mystery esteem". Next, the Secret worth is encoded utilizing the SSA to make input-yield sets. These sets can later be joined during the unscrambling procedure to figure out which records are genuine records and phony records. The produced info yield sets (not simply the Secret worth) are then put away in independent mists. That way, adequate data exists to figure out which records are genuine records, however this data is clouded by its divided and dispersed nature.

An assailant would need to interface with an adequate number of mists and consolidate the info yield sets put away there to figure out which records are genuine and counterfeit, which should be an outlandish undertaking given that the aggressor won't really know what number of mists the data is put away in, which mists are being utilized, nor that the information put away in the mists are divided. The more mists that an assailant needs to bargain so as to decide the Secret worth, the more powerful the security will be. As another additional layer of security, the info esteems from the information yield sets are never put away in a database, simply the yield esteems are. Just the client knows the information values. So not only will an attacker have to compromise a bunch of cloud databases to own enough data to decrypt the initial table hold on there, they are going to even have to guess or steal the input values that area unit solely ever entered on the user's secure laptop computer. These values may well be set to at random rotate throughout each info conceive to additional guard the user's knowledge. Once the inputoutput pairs from the SSA area unit hold on within the clouds and also the info association is closed, the user should later be ready to pull all of that knowledge back along so as to reconstruct the read of real records. a straightforward method handles the View's reconstruction. First, a association is created to the cloud tables to gather the output values hold on there. These area unit as well as the tables input values to create SSA input-output pairs. Next, the input-output pairs area unit consolidated exploitation mathematical interpolation to see the initial SSA polynomial from that they were created.

Once the polynomial is recreated, the key constant term is extracted from the polynomial operate and therefore the equation is discarded. This method is represented [3] the key whole number term is last decoded into the list of real records, that is employed to mix the record fragments into a read consisting of solely the important records. The coding method is represented [3]. The read is formed once the formula starts its initial cloud association method and is born once the formula completes its execution, that ensures that the important illustration of the user's information solely exists for as long because the user is interacting with it. These processes are depicted at a high level in Figure 5.

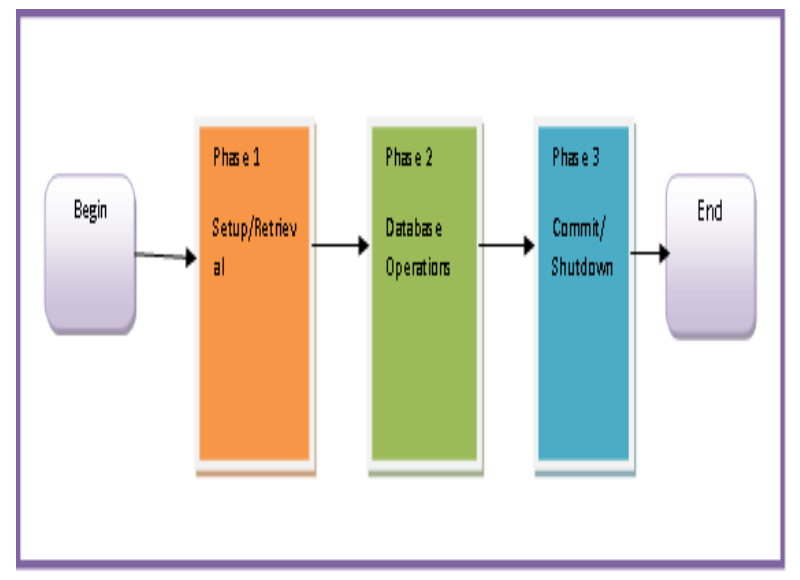

Figure 5: Three fundamental phases taken during the Hoeppner Security Algorithm

Above Figure - The Hoeppner Security Algorithm at a High Level Phase 1, the Setup stage, is liable for making a neighborhood working duplicate of the entirety of the remote cloud database tables (the tables put away in the mists) used to build the database View, recovering the information yield sets from the nearby tables, consolidating them to decide the Secret worth, and developing the database View of genuine records from the Secret worth.

Stage 2 enables the client to connect with the View as though it was an ordinary, non-disseminated database after the View is developed. When a client is prepared to submit their progressions or to close down their database association, the third stage, Commit/Shutdown, is authorized.

Third stage makes the mystery esteems from the genuine records put away in the database, and stores the yield esteems made from by applying Shamir's SSA into the nearby table duplicates, moves the refreshed neighborhood tables to supplant their partners in the remote cloud databases, and afterward decimates the database View and any privately replicated tables if the database is being closed down.

\section{Comparative study of Security algorithms}


Throughout the years, a wide range of encryption plans have been made so as to ensure touchy information. A few of these security plans have been applied to the cloud. When sending touchy data over the web to the cloud, for example, secure conventions like HTTPS are regularly utilized. At the point when information are put away in the cloud, clients ordinarily encode them so that, in case of a security rupture, programmers must translate the information so as to utilize them. The paper "Distributed computing, Security and Data Concealment" recommends that this security isn't adequate for the cloud [Delettre11]. At the point when clients transfer their databases to the cloud, they upgrade their databases' vulnerabilities in light of the fact that their information are currently put away in the semi-open cloud engineering and are facilitated by a potentially faulty association. In spite of the fact that information might be secure during transmission and keeping in mind that encoded within the database, an undertaking's metadata, or data about the fundamental information, are as yet helpless [Delettre11] In order to prevent hackers from taking any data, including metadata, from an enterprise, Delettre [1] proposed a Data Concealment solution to provide the security for the user's confidential information in the cloud databases. In this method some artificial data has been added along with the real data of the user, so that it creates ambiguity to the unauthorized users, it cannot be easily identified by the unauthorized users. In this approach we have a data concealment security component it achieves the data security in cloud database. Though this approach can augment information and data security, it conjointly having drawbacks. First, it'll be tough to form a worth generator that's capable of making realistic strings. so as for it to be passed-off as thinkable, the generator should build strings that area unit semantically correct, given the sort of information that area unit hold on within the information. specialised generators is also required for every information or information sort. The second potential downside to the current security theme is decisive that information things area unit the userimputed ones and that area unit faux information.

"Using Multi-clouds to confirm Security in Cloud Computing," Mr. Alzain suggests storing a database's records across many various clouds [Alzain2]. This not solely will increase a database's security, however conjointly adds to the cloud's fault tolerance and information accessibility. to grasp however Alzain's planned rule works and the way these edges pop out, think about the some example of associate degree insertion and retrieval request situation mistreatment Alzain's rule. To insert a record into the multi-cloud cluster, 1st it's sent to a server wherever the record is variable into teams of attributes (one cluster per cloud), so every cluster of attributes information is individually enciphered by mistreatment Shamir's Secret Sharing rule (SSA). The encrypted values area unit then hold on within the cloud databases rather than the plain text values. To retrieve a record, every a part of the record is $1 \mathrm{st}$ collected from the various clouds so mistreatment interpolation, every set of encrypted values is combined to undo the SSA's encoding methodology. Finally, all of the decrypted values area unit place along to make the record that was sent to the cloud, that is came back to the user [Alzain2]. Hoeppner Security rule (HSA) [3] arrangement utilizes totally different mists and phony records to feature further layers of security to the cloud information. every cloud used in this calculation ought to be from an alternate CSP and in each cloud a particular property or gathering of properties of each record are put away. The Hoeppner Security Algorithm (HSA) parts both genuine and counterfeit records information over the mists so as to expand the security of cloud databases and darken the client's metadata impression.

"Po1 Program" is the java usage of this calculation. The proficiency of Po1 Program was evaluated against the "Alzain Program," a usage of the calculation adjusted from [2]. The Alzain Program didn't furnish clients with the adaptability to characterize precisely how their information were separated over the mists as the Pol Program did, yet despite everything it end up being a helpful relative system.

Numerous tests were run against the two projects. The initial scarcely any tests decided how well the calculations had the option to part database records up among the mists. The Po1 Program settled in to be more flexible and productive than the Alzain Program. It enables clients to split their records up by trait, gatherings of qualities, and by gatherings of characters inside a characteristic before putting each gathering of information into their preferred cloud database. The Alzain Program doesn't furnish the client with about a similar degree of adaptability in how their information are circulated, and it sets aside any longer effort to finish its encryption procedure. It is end up being progressively effective at bringing prior tables into its scrambled plan, however, indicating that a portion of the Po1 Program's expanded safety efforts can prompt longer execution times. The expansion of progressively number of mists and tables to the encryption conspire builds the Po1 Program's general execution time, yet additionally helps its general security by expanding the quantity of mists that must be undermined for an enemy to decode the client's information.

The Po1 Program investigated the expenses related with expansion of additional mists to an encryption plan, and how the proportion of genuine to counterfeit records influences execution time. In the two cases, it was discovered that including more mists and phony records 
to the HSA is a simple method to build the database's security without extraordinarily impacting its execution time. Different aspects of security were considered, for example, how expanding the quantity of records being scrambled by the Po1 Program builds the measure of time a savage power assault would take. It was presumed that the Alzain Program is most secure when encoding long records while the Pol Program is most secure when scrambling tables containing numerous records. All in all, the Pol Program has exhibited that the HSA is most appropriate for the encryption of tables containing numerous records. Security gains are made for each cloud and record (both genuine and counterfeit) added to the encryption plot. In any case, the HSA requires an expanded measure of extra room for its SSA keys each time more records are embedded. The HSA additionally isn't appropriate for fast table import methodology. Bringing in prior tables is certifiably not a run of the mill use case, however, so the Pol Program's moderate execution isn't as exorbitant as it shows up.

\section{Conclusion and Future Scope}

This paper discussed about various data security issues in cloud databases and traditional databases and also presented the comparison of data security properties in traditional and cloud databases. The focus of this research is on survey about Cloud Database Security algorithms, here we focused on three important algorithms: Multi Cloud Database Model (MCDB), Data concealment and Hoeppner Security Algorithm (HSA) and also studied merits and demerits of those Algorithms.

\section{References}

1. Christian Delettre, KarimaBoudaoud - Michel Riveill, IEEE,( 2011)

2. Mohammed A. AlZain, Ben Soh and Eric Pardede,MCDB: ICDASC 2011 (2011)

3. Hoeppner, Joseph A.,UNF Theses and Dissertations, (2015).

4. M. A. AlZain and E. Pardede, HICSS, pp. 1-9.( 2011)

5. R. Agrawal, P. J. Haas, and J. Kiernan. VLDB J., 12(2) :157-169 (2003)

6. F. H. Wang, X. Cui, Z. Cao. ISIP. (2008).

7. M. A. Alzain and E. Pardede, Hawaii International Conference on System Sciences HICSS2011, pp. 1-9( 2011)

8. Akashdeep Bhardwaj*, GVB Subrahmanyamb, Vinay Avasthic, ICCMS (2016)

9. Priyadarshini Patila, Prashant Narayankarb, Narayan D, Meena S MdA, ICISP2015, 11-12 (2015).
10. Erick Fernando, Dine Agustin, Muhamad Irsan, Dina Fitria Murad, Hetty Rohayani, Dadang Sujana, ICSIET (2019)

11. Bih-Hwang Lee, Ervin Kusuma Dewi, Muhammad Farid Wajdi, WOCC2018 (2018)

12. Amjad Alsirhani, Peter Bodorik, Srinivas Sampalli, ICCA (2017)

13. Tao Xiang a, Xiaoguo Li a, Fei Chen b, Yuanyuan Yang c, Shengyu Zhang, JPDC. (2017)

14. Md. Alam Hossain, Md. Biddut Hossain, Md. Shafin Uddin, Shariar Md. Imtiaz, IJARCSSE, Volume 6 (2016)

15. Mr. Manish M Poteya,Dr C A Dhoteb,Mr Deepak H Sharmac, ,ICCCV (2016)

16. S.Rajeswari,R.Kalaiselvi, ICCS ( 2017).

17. K. Madhavi, G. Ramesh, K. Sowmya, CICIT, pp 630-636 (2019).

18. Prasanna Lakshmi, K., Reddy, C.R.K., ICNIT 2010 , pp. 451(2010)

19. Kumar, S.K., Reddy, P.D.K., Ramesh, G., Maddumala, V.R.,Image transformation technique using steganography methods using LWT technique Traitement du Signal, 36 (3), pp. 233-237.(2019).

20. Usha Kumari, Ch., Jeevan Prasad, S., Mounika, G.,Leaf ICCMC2019, pp. 1095-1098(2019).

21. Dhanalaxmi, B., Apparao Naidu, G., Anuradha, K.,Adaptive, Procedia Computer Science, 46, pp. 432-442 (2015) 